Article

\title{
Integrable Near-Infrared Photodetectors Based on Hybrid Erbium/Silicon Junctions
}

\author{
Mariano Gioffré (1), Giuseppe Coppola, Mario Iodice (1) and Maurizio Casalino * \\ Institute for Microelectronics and Microsystems, National Research Council, I-80131 Napoli, Italy; \\ mariano.gioffre@cnr.it (M.G.); giuseppe.coppola@cnr.it (G.C.); mario.iodice@cnr.it (M.I.) \\ * Correspondence: maurizio.casalino@na.imm.cnr.it; Tel.: +39-81-613-2345
}

Received: 28 September 2018; Accepted: 29 October 2018; Published: 3 November 2018

\begin{abstract}
This paper presents the design, fabrication, and characterization of Schottky erbium/silicon photodetectors working at $1.55 \mu \mathrm{m}$. These erbium/silicon junctions are carefully characterized using both electric and optical measurements at room temperature. A Schottky barrier $\Phi_{\mathrm{B}}$ of $\sim 673 \mathrm{meV}$ is extrapolated; the photodetectors show external responsivity of $0.55 \mathrm{~mA} / \mathrm{W}$ at room temperature under an applied reverse bias of $8 \mathrm{~V}$. In addition, the device performance is discussed in terms of normalized noise and noise-equivalent power. The proposed devices will pave the way towards the development of Er-based photodetectors and light sources to be monolithically integrated in the same silicon substrate, and both operating at $1.55 \mu \mathrm{m}$.
\end{abstract}

Keywords: silicon; near-infrared; photodetectors; internal photoemission; erbium

\section{Introduction}

Integrated photonics refers to the fabrication and integration of several photonic components on the same planar substrate. These components include beam splitters [1], gratings [2], couplers [3], interferometers [4], sources [5], and detectors [6], among others. In the last three decades, there has been growing interest in the use of silicon ( $\mathrm{Si}$ ) as a substrate for integrated photonics [7]. In this context, tremendous progress has been made in Complementary Metal Oxide Semiconductor (CMOS) technological processes based on the use of silicon-on- insulator (SOI) substrates. Now it's possible to obtain reliable and effective optical components which are fully compatible with CMOS technology, such as low-loss waveguides, high-Q resonators, high-speed modulators, and couplers, typically operating at near-infrared wavelengths [5,8-12].

However, the silicon indirect band-gap and the minimal optical absorption at NIR wavelengths limit the use of $\mathrm{Si}$ for some active optical components like sources (leds, lasers) or NIR photodetectors (PDs).

The latter issue is typically addressed by the integration with Germanium (Ge). Unfortunately, the growth of $\mathrm{Ge}$ on a Si substrate is only achievable with a two-step epitaxial growth technique $[13,14]$ that causes problems in both the thermal budget and planarity [6], hindering the monolithic integration of an electronic and photonic circuit on the same Si substrate. Indeed, Intel [15] and Luxtera [16] reported on a four-channel optical receiver working at $50 \mathrm{Gbps}$ and $40 \mathrm{Gbps}$, respectively, based on Ge PDs that are separately fabricated, and only subsequently flip-chip-mounted to a Si electronic circuit. In addition, good progress has been made in fabricating SiGe-based PDs in such a "zero-change" CMOS process flow [17], with the Ge content of the available layer estimated to be $25 \%$ to $35 \%$ [18]; however, in this case, the wavelength of possible detection is limited to less than $1200 \mathrm{~nm}$ [19]. Thanks to this technological progress, a single-chip microprocessor integrating over 70 million transistors and 850 photonic components has been fabricated, taking advantage of SiGe PDs fabricated by a "zero-change" 
CMOS approach operating at $1180 \mathrm{~nm}$ [20]. Unfortunately, no Ge-based PDs operating at $1550 \mathrm{~nm}$ have been realized by a "zero change" approach as far.

In contrast to traditional semiconductors, lead sulfide $(\mathrm{PbS})$ quantum dots $(\mathrm{QD})$ combined with a conjugated polymer (MEH-PPV) have been used for infrared PDs [21]. These devices are characterized by a maximum responsivity of $3.1 \times 10^{-3} \mathrm{~A} / \mathrm{W}$ at $975 \mathrm{~nm}$ and under $-5 \mathrm{~V}$ bias, showing also the capability of detecting longer wavelengths $(980 \mathrm{~nm}, 1.200 \mu \mathrm{m}$ and $1.355 \mu \mathrm{m})$ by varying the QD size. $\mathrm{PbS}$ QDs have also been deposited via a spin-casting process on top of a graphene layer in order to increase the sensitivity of a digital camera operating at both visible and short-wave wavelengths [22]. However, both PbS QDs and graphene have not yet fully demonstrated their automated integration in Si technology for volume fabrication. This is because, very often, an all-Si approach is preferred [23]. The internal photoemission effect (IPE) is commonly exploited as an option for the Si sub-bandgap detection [23]. IPE is the photo-excitation of the carriers in a metal layer to energies higher than the Schottky barrier and the emission of these carriers to the conduction band of the semiconductor [24]. In recent years, many IPE-based PDs on Si, including Schottky PDs [25], metal-semiconductor metal (MSM) PDs [26], and surface plasmon polariton (SPP) PDs [27], have been reported. However, their external responsivity rarely exceeds the tens of $\mathrm{mA} / \mathrm{W}$. Most recently, the use of graphene monolayers in place of metal has demonstrated the possibility of reaching responsivities as high as $0.37 \mathrm{~A} / \mathrm{W}$ at $1550 \mathrm{~nm}$ [28]. It is worth mentioning that the aforementioned PDs are based on waveguide structures that are typically more responsive with respect to the vertically-illuminated counterpart, in which the light-matter interaction is strongly reduced [29].

On the other hand, thanks to the success of the so-called EDFA (Erbium-doped fiber amplifier) used in telecommunications, in recent years, much effort has been made to introduce $\mathrm{Er}$ in $\mathrm{Si}$ in order to realize Si-based light sources. Unfortunately, $\mathrm{Si}$ is not a good host for Er. The reason is believed to be linked to a back-transfer process of energy that strongly reduces the light emission at room temperature. The attractive features of this technology are the emission in the telecommunications band of $1550 \mathrm{~nm}$, as well as electrical pumping. For this application, metal-oxide-semiconductor (MOS) structures are typically realized. A voltage applied between metal and $\mathrm{Si}$ causes electrons to tunnel through the oxide in which Er ions are dispersed, exciting them. In a subsequent version of the device, Si nanocrystals are dispersed together with Er ions in the oxide. Light emitting diodes based on this approach show efficiencies of about 10\% as reported by STMicroelectronics [30], even if the light emission is observed to diminish when the current density increases. This effect is believed to be due to free carrier absorption and Auger processes; thus, despite preliminary successes, many concerns need still to be addressed.

Although Erbium is a very promising material for the realization of Si-based LASER, no investigations have been performed on the use of hybrid $\mathrm{Er} / \mathrm{Si}$ structures in the field of near-infrared detection. Indeed, this could be very fascinating in the vision of integrating both Er-based LASERs and PDs on the same silicon substrate. In addition, Er can be deposited by sputtering at low temperature without compromising pre-existing electronic circuitry. On the other hand, sputtered Er deposited on Si has already been shown to be capable of forming Schottky junctions [31] that have been widely employed in both infrared and NIR detection [26,27,32-34].

In this work we report on Er-based Schottky PDs operating at $1550 \mathrm{~nm}$ and integrated with a double-polished $200 \mu \mathrm{m}$-thick Si substrate. Er has been deposited by a radio-frequency (RF) sputtering process at low temperature, and its optical properties have carefully been characterized by ellipsometric techniques. The photocurrent generation is based on the internal photoemission effect, where photoexcited carriers from Er are emitted into Si over the Schottky barrier $\Phi_{\mathrm{B} 0}$. The rectifying Schottky diode behavior is shown from the IV curve, from which both the series resistance and the ideality coefficients are extrapolated together with a Schottky barrier $\Phi_{\mathrm{B} 0}$ of $\sim 673 \mathrm{meV}$. We show that an external responsivity (photogenerated current-incident optical power ratio) of $R_{\text {ext }} \sim 0.29 \mathrm{~mA} / \mathrm{W}$ at $1 \mathrm{~V}$ reverse bias can be obtained; this value increases to $\sim 0.55 \mathrm{~mA} / \mathrm{W}$ when a reverse voltage of $8 \mathrm{~V}$ is 
applied. We believe that this work paves the way for the realization of microsystems where Er-based sources and photodetectors are monolithically integrated onto the same Si substrate.

\section{Materials and Methods}

\subsection{Erbium Deposition}

The Erbium thin film was deposited directly on the Si substrate by a Radio-Frequency (RF) Sputtering technique from a 99.9\% pure metal Er target, by an Argon gas process. The substrate was placed on the holder, and before the deposition process, the chamber was pumped down to a base pressure of $3 \times 10^{-6}$ mbar. A 30 min presputtering process at $150 \mathrm{~W}$ RF power was necessary to overcome the target surface oxidation. An Er film was then deposited at room temperature, with $30 \mathrm{~W}$ RF power, at $2.5 \times 10^{-2}$ mbar pressure, with a constant $40 \mathrm{sccm}$ Ar flux and 11 min deposition time.

\subsection{Erbium Ellipsometric Characterization}

Spectroscopic ellipsometry data were recorded using a phase-modulated spectroscopic ellipsometer (UVSEL, Jobin Yvon Horiba, Palaiseau, France) with a wavelength scanning range from 300 to $1600 \mathrm{~nm}$, at an incident angle of $70^{\circ}$. Acquired data were fit to an optical model of the sample in which the dispersion of the erbium film was assumed to follow a classical dispersion model [35,36], based on the sum of the single and double Lorentz, and Drude oscillators:

$$
\widetilde{\varepsilon}(\omega)=\varepsilon_{\infty}+\frac{\left(\varepsilon_{s}-\varepsilon_{\infty}\right) \cdot \omega_{t}^{2}}{\omega_{t}^{2}-\omega^{2}+j \Gamma_{0} \cdot \omega}+\frac{\omega_{p}^{2}}{-\omega^{2}+j \Gamma_{d} \cdot \omega}+\sum_{i=1}^{2} \frac{f_{i} \cdot \omega_{0 i}^{2}}{\omega_{0 i}^{2}-\omega^{2}+j \cdot \gamma_{i} \cdot \omega}
$$

The Lorentz oscillator model works well for insulators and semiconductors above the band gap, while the Drude model describes well the optical properties of metals but does not take into account the notion of optical band gap energy, Eg. The combination of both is often adequate when the material is a little conductive and has a metallic character. In our case, for the erbium dielectric function assessment, only one of the two oscillators of the last term was introduced. Fitting of experimental data leads to film thickness and dielectric function $\widetilde{\varepsilon}=\varepsilon_{1}-j \varepsilon_{2}$ evaluation; the complex refractive index comes from the dielectric function, assuming that $\widetilde{\varepsilon}=n^{2}=(n-j k)^{2}$. The film structure used in the model consists of a homogeneous bulk erbium film and an outmost layer, described by a Bruggeman effective medium approximation (BEMA) [37].

\subsection{Electrical Characterization}

The PD electrical characterization consisted of the measurement of the current-voltage (I-V) characteristics of the Er/p-Si Schottky junction, where p-Si is biased with respect to grounded Er electrode. The I-V characteristics were acquired using a Keithley 6487 picoammeter. The I-V characteristic is the mean of five curves that were obtained by varying the voltages repetitively from $-8 \mathrm{~V}$ to $2 \mathrm{~V}$ and vice-versa.

\subsection{Optoelectronic Characterization}

For optoelectronic characterization, a tunable NIR laser (AQ4321D, Ando, San Jose, CA, USA) was collimated, chopped, and split into two beams using a beam splitter. One beam was focused by a $20 \times$ IR microscope objective (MO) to the device under test (DUT). The transmitted light was collected using a $20 \times$ IR collecting MO and addressed on a NIR CCD to simplify the alignment procedure. A lock-in amplifier was used to measure the photocurrent produced by the DUT. The second beam was sent to a calibrated commercial power meter to perform incident optical power measurements, and consequently, to calculate the external responsivity. 


\section{Results and Discussion}

\subsection{Fabrication and Theoretical Background}

A bi-polished $200 \mu$ m-thick very lightly-doped P silicon was used to fabricate the device reported in Figure 1. A slightly doped substrate was chosen $\left(\sim 10^{15} \mathrm{~cm}^{-3}\right)$ in order to avoid free carrier absorption.

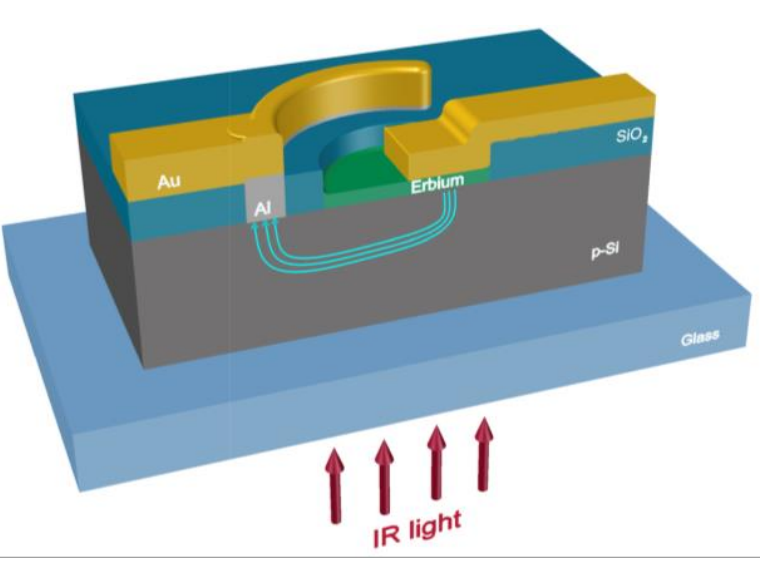

(a)

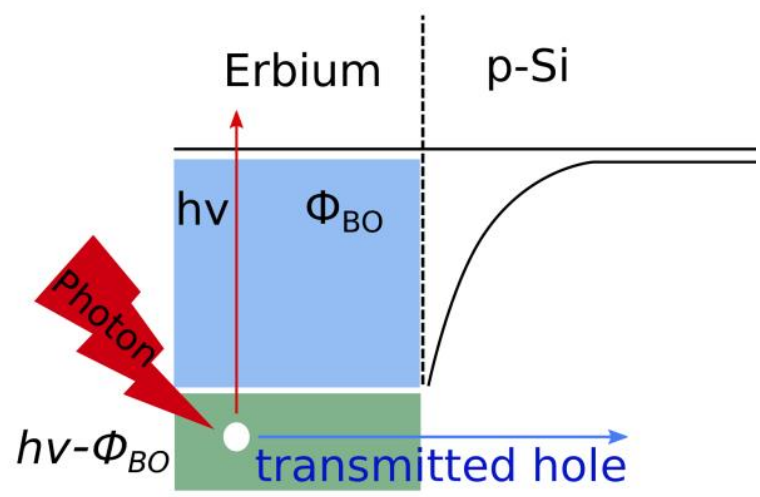

(c)

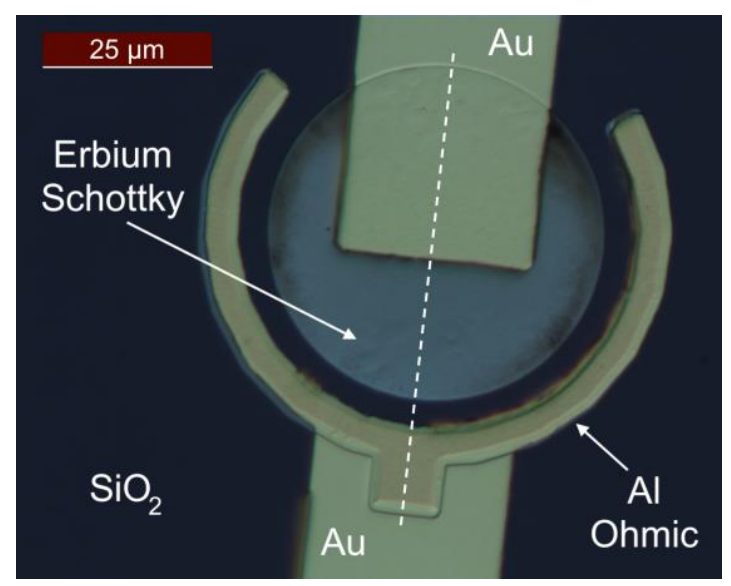

(b)

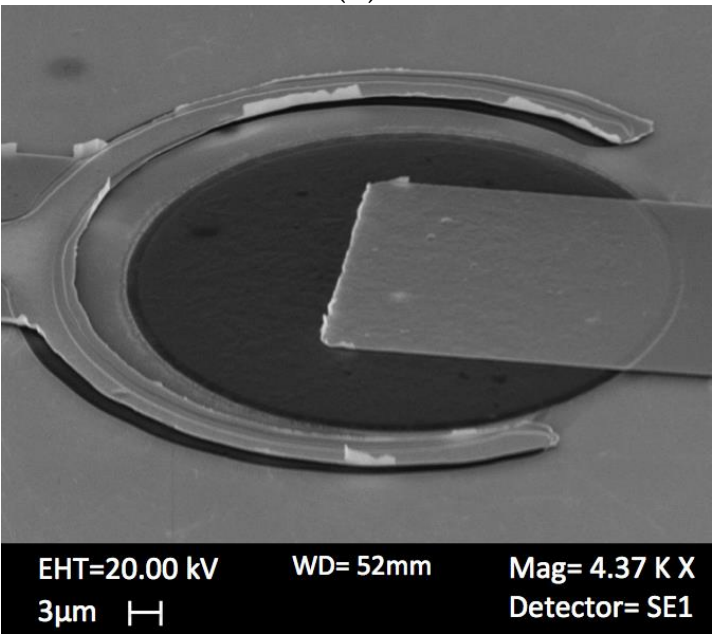

(d)

Figure 1. (a) Schematic cross-sectional view of the Erbium/Si Schottky PD under illumination; (b) optical image of a sample device; (c) the IPE mechanism in a Er/p-Si Schottky junction, where $\mathrm{E}_{\mathrm{F}}$ is the Fermi energy of the metal, $E_{V}$ is the Si valence band energy, and $h v-\Phi_{B}$ is the difference between the photon energy and the Schottky barrier; (d) SEM image of the device.

The first step was a standard RCA cleaning process to remove any contaminants from the Si surface. Then, the Si substrate was thermally oxidized in order to obtain a $100 \mathrm{~nm}$-thick silicon dioxide $\left(\mathrm{SiO}_{2}\right)$. The two electrodes, the collecting Ohmic contact and the Schottky contact, were both realized on the top of the substrate. The collecting contact was made by a ring of $200 \mathrm{~nm}$-thick aluminium film, thermally evaporated at $3 \times 10^{-6} \mathrm{mbar}$ and $150{ }^{\circ} \mathrm{C}$.

First of all, the Shipley S1813 photoresist (PR) was deposited by spin coating at $4000 \mathrm{rpm}$, resulting in a PR thickness of $1.4 \mu \mathrm{m}$. Then, a standard photolithography process was used to form a ring pattern. After that, $\mathrm{a} \mathrm{SiO}_{2}$ wet etching process was performed, and after the aluminium thermal evaporation, a lift-off process was carried out in order to obtain direct contact between $\mathrm{Al}$ and $\mathrm{Si}$. Then, an annealing at $475{ }^{\circ} \mathrm{C}$ in nitrogen for $30 \mathrm{~min}$, to obtain not-rectifying behaviour, was carried out. 
The Schottky contact was fabricated by sputtering deposition of $50 \mathrm{~nm}$-thick erbium film. The top of the wafer was covered by Shipley S1813 PR, exposed, and developed in order to obtain a disk surrounded by the $\mathrm{Al}$ ring Ohmic contact. Then, $\mathrm{S} \mathrm{SiO}_{2}$ wet etching process was performed in order to deposit the Erbium in such a way that it was in direct contact with Si.

Then, the Erbium active materials were deposited as reported in the Section 2, and subsequently patterned. Finally, two gold ( $\mathrm{Au}$ ) electrodes have been realized by standard pholitography and lift-off process in order to connect both the Schottky (Er) and Ohmic (Al) contacts of the device to the macroscopic world. Finally, the sample was fixed onto a glass support, as shown in Figure 1a.

Internal quantum efficiency of Si-based Schottky PDs can be written as $\eta_{\text {int }}=C \cdot \frac{\left(h v-\Phi_{B}\right)^{2}}{h v}[38,39]$, where $C$ is the quantum efficiency coefficient, $h v$ is the energy photon, and $\Phi_{\mathrm{B}}$ is the Schottky barrier height $(\mathrm{SBH})$. On the other hand, $\eta_{\text {int }}$ is linked to the external responsivity $\eta_{\text {ext }}=A \cdot \eta_{\text {int }}$, where $\mathrm{A}$ is the metal absorption; this can be written as:

$$
A=(1-R) \cdot\left(1-e^{-\alpha \cdot d}\right)
$$

where $R$ is the reflectivity at the metal/Si interface, $\alpha$ and $d$ are the absorption coefficient and thickness of the metal, respectively. The absorption coefficient $\alpha$ is linked to the penetration depth $\delta=1 / \alpha \alpha$; thus, in the limit of metal thickness $d>>\delta$, all optical power going into the metal will be absorbed and $A=1-R$. This means that the lower the reflectivity, the higher the absorption (and the higher the efficiency). The corresponding external responsivity can be written as [37]:

$$
R_{e x t}=\frac{q}{h v} \cdot \eta_{e x t}=(1-R) \cdot C \cdot \frac{\left(h v-\Phi_{B}\right)^{2}}{h v^{2}}\left[\frac{A}{W}\right]
$$

\subsection{Erbium Charactherization}

Figure 2 shows the ellipsometric characterization carried out on the sputtered Er in terms of the complex refractive index and reflectivity.

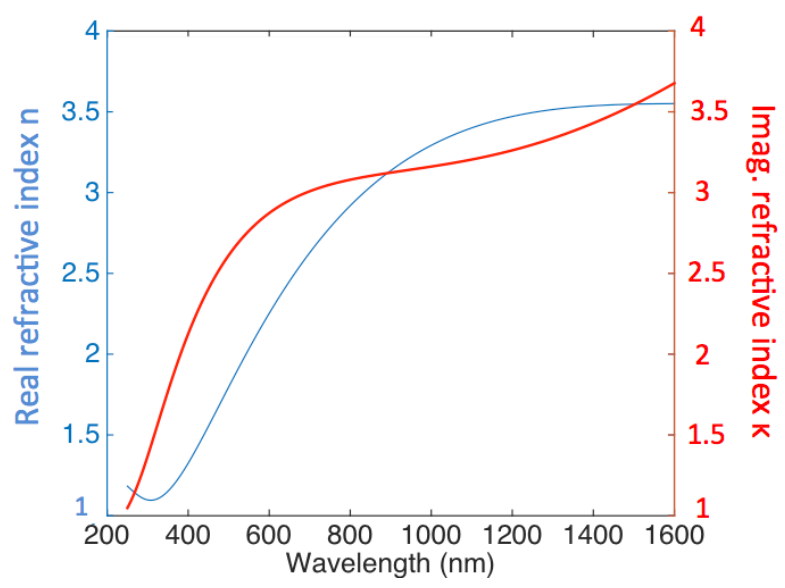

(a)

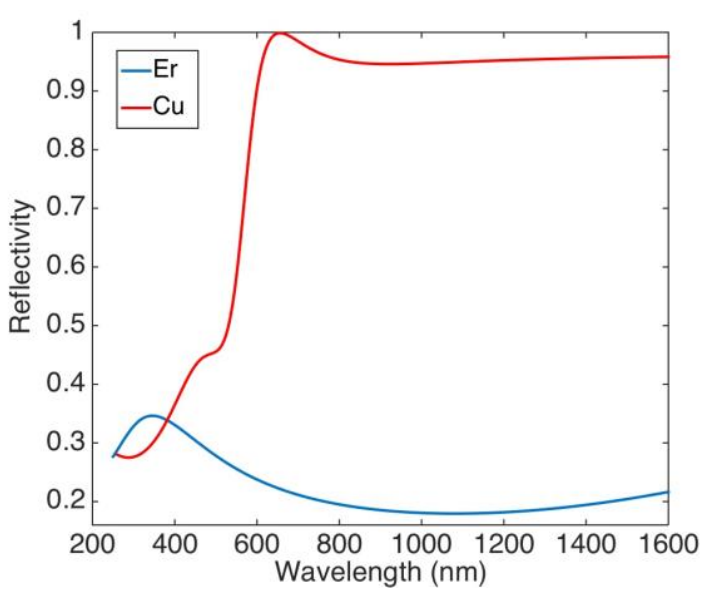

(b)

Figure 2. (a) Real (blue) and imaginary (red) refractive index of sputtered Er measured by ellipsometric characterization; (b) simulated reflectivity at both $\mathrm{Si} / \mathrm{Cu}$ and $\mathrm{Si} / \mathrm{Er}$ interface for normal incidence.

Figure 2a shows that Er is characterized by an extinction coefficient of $\kappa=3.68$ at $\lambda_{0}=1550 \mathrm{~nm}$; this leads to an absorption coefficient $\left(\alpha=4 \pi \kappa / \lambda_{0}\right)$ and penetration depth $(\delta=1 / \alpha)$ of $29.8 \mu \mathrm{m}^{-1}$ and $33.6 \mathrm{~nm}$ at $1550 \mathrm{~nm}$, respectively. By using the Fresnel coefficient for normal incidence, the reflectivity of the $\mathrm{Si} / \mathrm{Er}$ interface is reported in Figure $2 \mathrm{~b}$, where the reflectivity of $\mathrm{Si} / \mathrm{Cu}$ interface is also reported for comparison. 


\subsection{Electrical Charactherization}

The Er/p-Si Schottky junction I-V experimental characteristics are shown in Figure 3a.

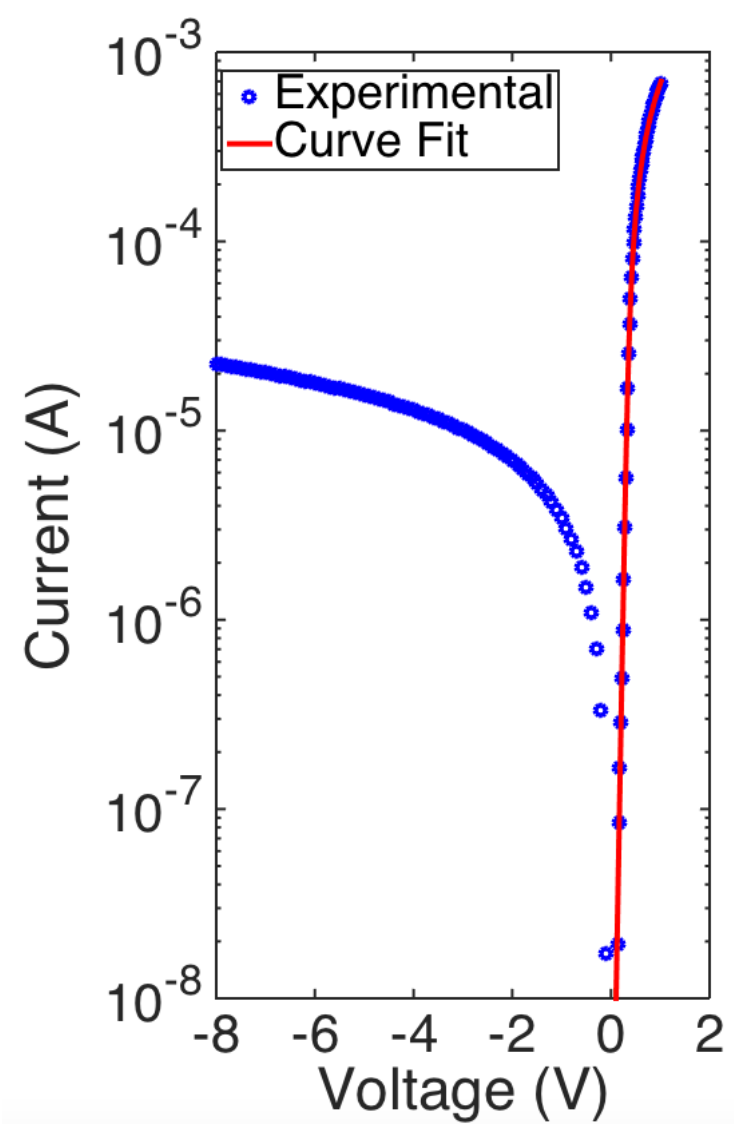

(a)

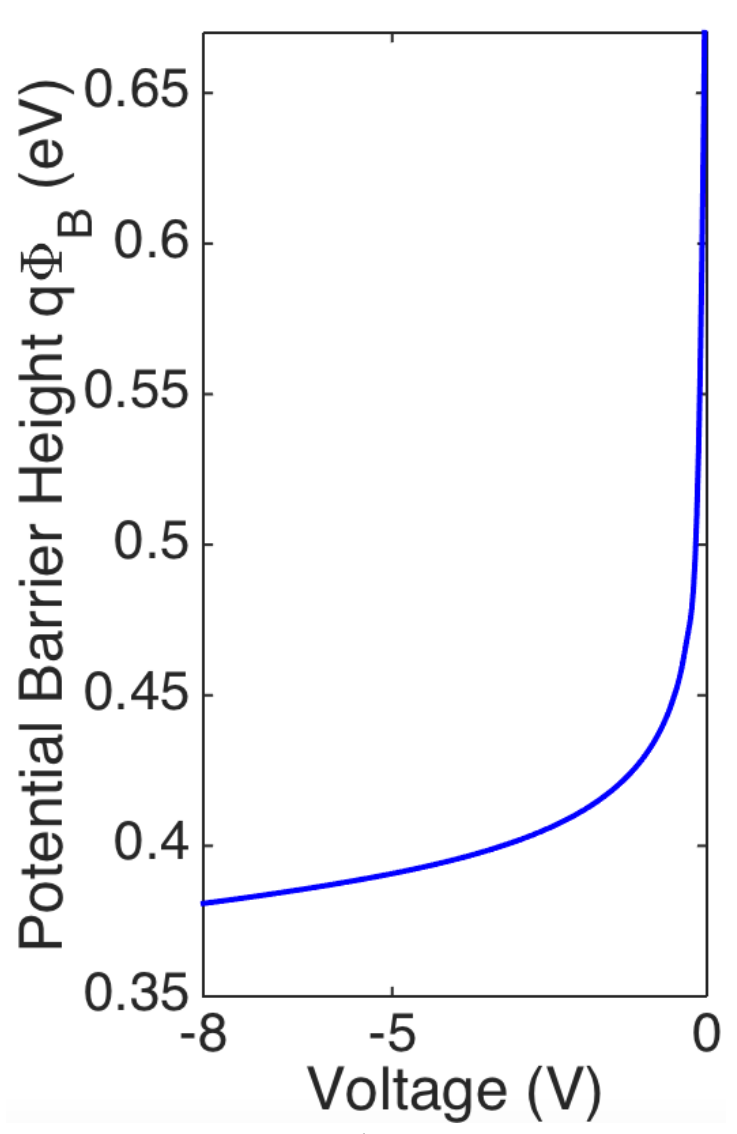

(b)

Figure 3. (a) I-V characteristics of Er/p-Si PD at room temperature; (b) potential barrier height as a function of reverse bias.

The device shows rectifying I-V diode behavior, which follows the Schottky diode equation [24]:

$$
\begin{gathered}
I=I_{S} \cdot\left(e^{\frac{q\left(V-R_{S} I\right)}{\eta k_{B} T}}-1\right) \\
I_{S}=A A^{*} T^{2} e^{-\frac{q \Phi_{B}}{k_{B} T}}
\end{gathered}
$$

where $\Phi_{B}(V)=\Phi_{B 0}-\Delta \Phi(V), \Phi_{B 0}$ is the SBH at zero voltage, $\Delta \Phi_{B}(V)$ is the SBH change due to applied voltage, $V$ is the external applied voltage, $A$ is the junction area, $A^{*}$ is the Richardson constant (32 A/ $\mathrm{cm}^{2} \mathrm{~K}^{2}$ for p-type $\left.\mathrm{Si}[40]\right), \eta$ is the diode ideality factor, defined as the deviation of the measured I-V curve from the ideal exponential behavior [40], and $k_{B} T \sim 26 \mathrm{meV}$ at room temperature. In the low injection regime $(V<0.51 \mathrm{~V})$, the device shows negligible series resistance, as highlighted from the linear behavior shown in Figure 3a; however, at higher voltages, the current deviates from the linearity, and $R_{S}$ cannot be neglected anymore. $\Delta \Phi_{B}(V)$ is significant in reverse bias where a barrier-lowering Schottky occurs due to image force effect [40], but it can be neglected in forward bias where $\Phi_{B} \sim \Phi_{B 0}$ can be assumed. We estimate SBH in forward bias by fitting the experimental data with Equations (3) and (4), and by using $\Phi_{B}, \eta$ and $R_{s}$ as fitting parameters. We get $\Phi_{B}=0.673 \pm 0.003 \mathrm{eV}, \eta=1.16 \pm 0.01$, and $R_{S}=823 \pm 3 \Omega$. An ideality factor $\eta$ close to the unity indicates that the $\mathrm{Er} / \mathrm{p}$-Si junction has a behaviour that can be well approximated by the canonical equation of the Schottky junctions. 
Figure $3 b$ shows the potential barrier height as a function of reverse bias: it has been plotted by reverting Equation (5) and taking $\mathrm{I}_{\mathrm{S}}$ as reverse current, which is experimentally measured and reported in Figure 3a. In the limit of $V \rightarrow 0$, this confirms a value of $\Phi_{B 0} \sim 0.67 \mathrm{eV}$. Finally, Figure $3 \mathrm{~b}$ shows the SBH dependence on the applied reverse voltage, and $\Delta \Phi_{B}$ up to $\sim 0.29 \mathrm{eV}$ at $V=-8 \mathrm{~V}$.

\subsection{Electro-Optical Characterization}

The setup described in the Figure 4 and Section 2 was used for optoelectronic characterizations. Figure 5 a plots the spectral response under various reverse voltages.

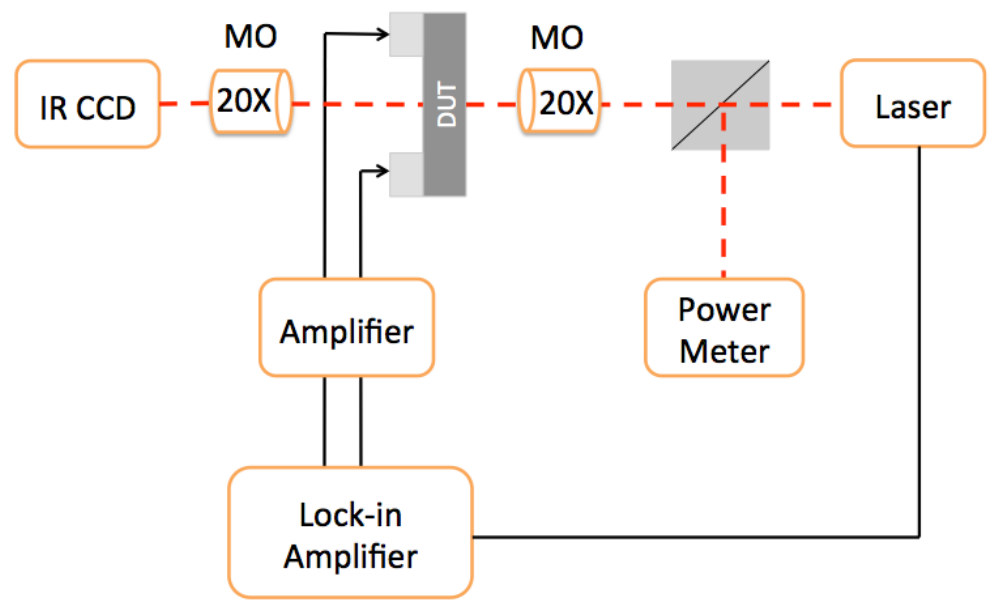

Figure 4. Experimental setup for opto-electronic experimental measurements.

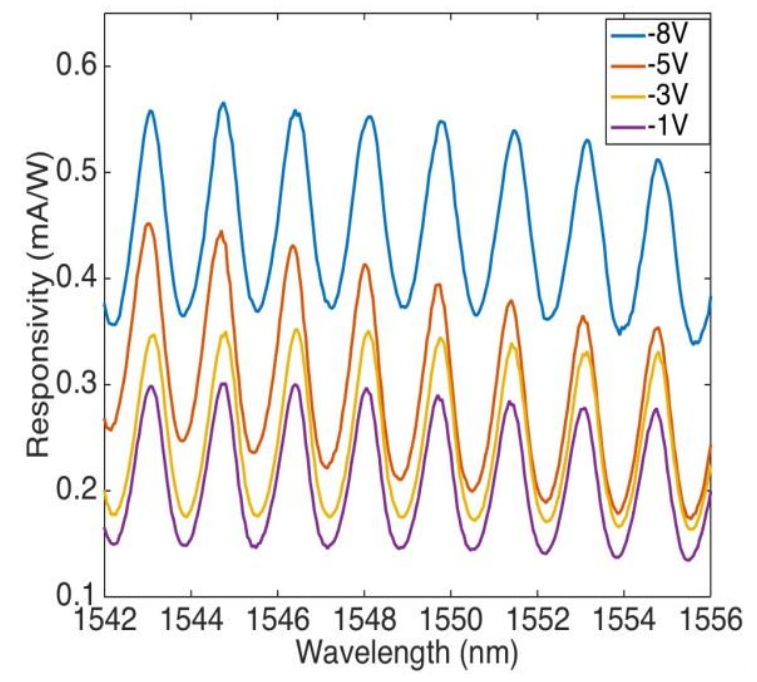

(a)

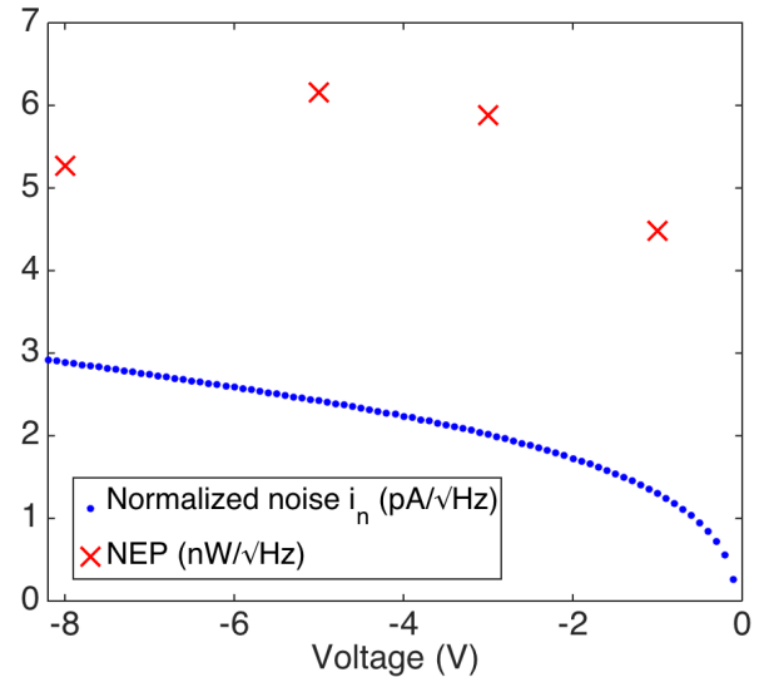

(b)

Figure 5. (a) Responsivity vs wavelength at different reverse biases; (b) NEP (red crosses) and total noise current in (blue dots) at different reverse biases.

For any reverse voltage, the device shows many resonance fringes. These are due to the $200 \mu \mathrm{m}$-thick silicon layer behaving as a low finesse Fabry-Perot microcavity; thus, when the wavelength is in agreement with the cavity length, the optical field is enhanced in the Si cavity, leading to increased Er absorption. The spectral separation between the peaks, named Free Spectral Range (FSR), is $\sim 1.7 \mathrm{~nm}$ in a very good agreement with the theoretical value of FSR $=\lambda^{2} / 2 n_{S i} L=1.73 \mathrm{~nm}$, being $\lambda=1550 \mathrm{~nm}$ the wavelength, and $n_{S i}=3.47$ [39] and $L=200 \mu \mathrm{m}$ the Si refractive index at 1550 $\mathrm{nm}$ and cavity length, respectively. As expected, at resonance we get photocurrent (responsivity) peaks 
due to increased absorption at the Er/Si interface. Maximum responsivity of around $1550 \mathrm{~nm}$ is $\sim 0.3$ at $-1 \mathrm{~V}$ of the applied reverse bias.

To further enhance $R_{\text {ext }}$, we exploit the Schottky barrier lowering effect and apply a larger (up to $8 \mathrm{~V})$ reverse bias to the PDs.

Figure 5a shows $R_{\text {ext }} \sim 0.55 \mathrm{~mA} / \mathrm{W}$ at $V=-8 \mathrm{~V}$ around $1550 \mathrm{~nm}$. It could be useful to mention that these devices show a responsivity more that is than two orders of magnitude higher than same device realized with copper $(\mathrm{Cu})$ [29]. This remark can be partially explained by considering that the $\mathrm{Er} / \mathrm{Si}$ interface is characterized by a reflectivity one order of magnitude lower than that of copper, as shown in Figure 2b. This leads to increased responsivity, as shown in Equation (3). It is worth noting that the slight change in peak height shown in Figure $5 \mathrm{a}$ is due to an overmodulation effect introduced by the glass support on which the sample is mounted, as shown in Figure 1a.

To estimate a noise figure of our PD, we calculate the amount of incident light power that generates a photocurrent equal to the noise current, i.e., the noise equivalent power (NEP), where NEP $=i_{n} / R_{\text {ext }}$ [41]. Moreover, we assume that shot (quantum) and Johnson (thermal) noise dominates the low-frequency $(1 / f)$ noise [42,43]. The shot $\left(i_{s}\right)$ and Johnson $\left(i_{j}\right)$ noise currents normalized to the spectral band $(1 \mathrm{~Hz})$ are given by $i_{s}=\left(2 q\left(I_{p h}+\mathrm{I}_{\mathrm{d}}\right)\right)^{1 / 2}[24]$ and $i_{j}=\left((4 \mathrm{kT}) / R_{e q}\right)^{1 / 2}[24]$, where $I_{p h}$ is the photocurrent, $I_{d}$ is the dark current, $R_{e q}=d V / d I$ is the equivalent resistance of a PD at reverse bias in dark, and $i_{n}=i_{j}+i_{s}$ is the normalized noise. Figure $5 \mathrm{~b}$ plots both NEP and $i_{n}$ as a function of the reverse bias applied $V$, and for $V=-8 \mathrm{~V}$, we get $i_{n} \sim 2.9 \mathrm{pA} / \mathrm{Hz}^{0.5}$ and NEP $\sim 5.3 \mathrm{nW} / \mathrm{Hz}^{0.5}$.

\section{Conclusions}

In conclusion, we have demonstrated a free-space Er-based PD for operation at $1.55 \mu \mathrm{m}$. The proposed devices are based on Er/pSi Schottky junctions, and their photodetection mechanism is based on internal photoemission. The Er/Si junction has been electrically characterized at room temperature, and a series resistance, ideality factor, and Schottky barrier of $823 \Omega, 1.16$ and $673 \mathrm{meV}$ have been achieved, respectively. It is worth noting that the ideality factor is close to the unity demonstrating that the Er/pSi junction can be very well described, taking advantage of the canonical theory on the Schottky structures.

The PDs are characterized by external responsivity of $0.29 \mathrm{~mA} / \mathrm{W}$ at $1 \mathrm{~V}$; this value increases up to $\sim 0.55 \mathrm{~mA} / \mathrm{W}$ with a reverse voltage of $8 \mathrm{~V}$. Finally, normalized noise and NEP have been discussed.

The results above indicate the possibility of the realization of Si-based free-space PDs that operate at $1.55 \mu \mathrm{m}$, taking advantage of the characteristics of the rare earth, Er. Moreover, it should be noted that the proposed device could be viewed as a low-finesse Fabry-Perot microcavity, where the Er absorption, and therefore, the device responsivity, can be periodically increased due to the enhancement of the optical field inside the Si cavity. In this context, responsivity may be enhanced through the use of high-finesse Fabry-Pérot optical microcavities, which have previously demonstrated their capabilities for the provision of greatly-increased absorption of the active medium [44]. In addition, the use of a high-finesse Fabry-Pérot optical microcavity would also be beneficial in terms of NEP.

The integration of Er in a standard CMOS process could be favored by the negligible thermal budget it requires, which has been deposited at room temperature. Since Er would be damaged during the high temperatures necessary for gate oxide growth, Er deposition should occur after gate processing but prior to the contact module. In this context and to achieve a full compatibility, it is mandatory to replace Au with metals that are compatible with CMOS technology. There are several advantages to monolithically integrating PDs with the rest of the receiver circuitry, including smaller parasitic capacitance and lower cost and scalability; the latter is very important for those applications where small-footprint PDs are required.

We believe that this work paves the way to the fabrication of Er-based sources and photodetectors that are monolithically integrated onto the same Si substrate. 
Author Contributions: Investigation, M.G., G.C., M.I. and M.C.; Project administration, M.C.; Writing-original draft, M.C.; Writing-review \& editing, M.G., G.C. and M.I.

Funding: This research received no external funding.

Acknowledgments: The authors would like to thank Vitaliano Tufano for his technical support and Ignazio Giglio for his preliminary contribution.

Conflicts of Interest: The authors declare no conflicts of interest.

\section{References}

1. Shen, B.; Wang, P.; Polson, R.; Menon, R. An integrated-nanophotonics polarization beamsplitter with $2.4 \times 2.4 \mu \mathrm{m}^{2}$ footprint. Nature 2015, 9, 378-382. [CrossRef]

2. Kintaka, K.; Kita, Y.; Shimizu, K.; Matsuoka, H.; Ura, S.; Nishii, J. Cavity-resonator-integrated grating input/output coupler for high-efficiency vertical coupling with a small aperture. Opt. Express 2010, 35, 1989-1991. [CrossRef] [PubMed]

3. Fang, Q.; Song, J.F.; Tao, S.H.; Yu, M.B.; Lo, G.Q.; Kwong, D.L. Low Loss ( 6.45 dB/cm) Sub-Micron Polycrystalline Silicon Waveguide Integrated with Efficient SiON Waveguide Coupler. Opt. Express 2008, 16, 6425-6432. [CrossRef] [PubMed]

4. Omran, H.; Medhat, M.; Mortada, B.; Saadany, B.; Khalil, D. Fully Integrated Mach-Zhender MEMS Interferometer with Two Complementary Outputs. IEEE J. Quantum Electron. 2012, 48, 244-251. [CrossRef]

5. Liu, A.; Rong, H.; Jones, R.; Cohen, O.; Hak, D.; Paniccia, M. Optical Amplification and Lasing by Stimulated Raman Scattering in Silicon Waveguides. J. Light. Technol. 2006, 24, 1440-1455. [CrossRef]

6. Wang, J.; Lee, S. Ge-Photodetectors for Si-Based Optoelectronic Integration. Sensors 2011, 11, 696-718. [CrossRef] [PubMed]

7. Jalali, B.; Fathpour, S. Silicon Photonics. J. Lightwave Technol. 2006, 24, 4600-4615. [CrossRef]

8. Rowe, L.K.; Elsey, M.; Tarr, N.G.; Knights, A.P.; Post, E. CMOS-compatible optical rib waveguides defined by local oxidation of silicon. Electron. Lett. 2007, 43, 392-393. [CrossRef]

9. Vivien, L.; Pascal, D.; Lardenois, S.; Marris-Morini, D.; Cassan, E.; Grillot, F.; Laval, S.; Fédéli, J.M.; El Melhaoui, L. Light Injection in SOI Microwaveguides Using High-Efficiency Grating Couplers. J. Light. Technol. 2006, 24, 3810-3815. [CrossRef]

10. Xu, Q.; Manipatruni, S.; Schmidt, B.; Shakya, J.; Lipson, M. 12.5 Gbit/s carrier-injection-based silicon micro-ring silicon modulators. Opt. Express 2007, 15, 430-436. [CrossRef] [PubMed]

11. Michael, C.P.; Borselli, M.; Johnson, T.J.; Chrystal, C.; Painter, O. An optical fiber-taper probe for wafer-scale microphotonic device characterization. Opt. Express 2007, 15, 4745-4752. [CrossRef] [PubMed]

12. Liu, A.; Liao, L.; Rubin, D.; Nguyen, H.; Ciftcioglu, B.; Chetrit, Y.; Izhaky, N.; Paniccia, M. High-speed optical modulation based on carrier depletion in a silicon waveguide. Opt. Express 2007, 15, 660-668. [CrossRef] [PubMed]

13. Eng, P.C.; Song, S.; Ping, B. State-of-the-art photodetectors for optoelectronic integration at telecommunication wavelength. Nanophotonics 2015, 4, 277-302. [CrossRef]

14. Michel, J.; Liu, J.; Kimerling, L.C. High-performance Ge-on-Si photodetectors. Nat. Photonics 2010, 4, 527-534. [CrossRef]

15. Alduino, A. Demonstration of a high speed 4-channel integrated silicon photonics WDM link with hybrid silicon lasers. In Proceedings of the IEEE Hot Chips 22 Symposium (HCS), Stanford, CA, USA, 22-24 August 2010; pp. 1-29. [CrossRef]

16. Narasimha, A.; Analui, B.; Balmater, E.; Clark, A.; Gal, T.; Guckenberger, D.; Gutierrez, S.; Harrison, M.; Koumans, R.; Kucharski, D.; et al. A 40-Gb/s QSFP Optoelectronic Transceiver in a $0.13 \mu \mathrm{m}$ CMOS Silicon-on-Insulator Technology. In Proceedings of the Optical Fiber Communication Conference/National Fiber Optic Engineers Conference, San Diego, CA, USA, 24-28 February 2008.

17. Harame, D.L.; Koester, S.J.; Freeman, G.; Cottrel, P.; Rim, K.; Dehlinger, G.; Ahlgren, D.; Dunn, J.S.; Greenberg, D.; Joseph, A.; et al. The revolution in SiGe: Impact on device electronics. Appl. Surf. Sci. 2004, 224, 9-17. [CrossRef]

18. Alloatti, L.; Srinivasan, S.A.; Orcutt, J.S.; Ram, R.J. Waveguide-coupled detector in zero-change complementary metal-oxide-semiconductor. Appl. Phys. Lett. 2015, 107, 041104. [CrossRef] 
19. Meng, H.; Atabaki, A.; Orcutt, J.S.; Ram, R.J. Sub-bandgap polysilicon photodetector in zero-change CMOS process for telecommunication wavelength. Opt. Express 2015, 23, 32643-32653. [CrossRef] [PubMed]

20. Sun, C.; Wade, M.T.; Lee, Y.; Orcutt, J.S.; Alloatti, L.; Georgas, M.S.; Waterman, A.S.; Shainline, J.M.; Avizienis, R.R.; Lin, S.; et al. Single-chip microprocessor that communicates directly using light. Nature 2015, 528, 534-538. [CrossRef]

21. Mcdonald, S.; Konstantatis, G.; Zhang, S.; Cyr, P.W.; Klem, E.J.D.; Levina, L.; Sargent, E.H. Solution-processed $\mathrm{PbS}$ quantum dot infrared photodetectors and photovoltaics. Nat. Mater. 2005, 4, 138-142. [CrossRef] [PubMed]

22. Goossens, S.; Navickaite, G.; Monasterio, C.; Gupta, S.; Piqueras, J.J.; Perez, R.; Burwell, G.; Nikitskiy, I.; Lasanta, T.; Galan, T.; et al. Broadband image sensor array based on graphene-CMOS integration. Nat. Photonics 2017, 11, 366-371. [CrossRef]

23. Casalino, M.; Coppola, G.; De La Rue, R.M.; Logan, D.F. State-of-the-art all-silicon sub-bandgap photodetectors at telecom and datacom wavelengths. Laser Photonics Rev. 2016, 10, 895-921. [CrossRef]

24. Casalino, M. Internal Photoemission Theory: Comments and Theoretical Limitations on the Performance of Near-Infrared Silicon Schottky Photodetectors. IEEE J. Quantum Elect. 2016, 52, 4000110. [CrossRef]

25. Zhu, S.; Yu, M.B.; Lo, G.Q.; Kwong, D.L. Near-infrared waveguide-based nickel silicide Schottky-barrier photodetector for optical communications. Appl. Phys. Lett. 2008, 92, 081103. [CrossRef]

26. Casalino, M.; Iodice, M.; Sirleto, L.; Rendina, I.; Coppola, G. Low dark current silicon-on-insulator waveguide metal-semiconductor-metal photodetector based on internal photoemission effect at $1550 \mathrm{~nm}$. J. Appl. Phys. 2013, 114, 153103. [CrossRef]

27. Berini, P. Surface plasmon photodetectors and their applications. Laser Photonics Rev. 2013, 8, 197-220. [CrossRef]

28. Goykhman, I.; Sassi, U.; Desiatov, B.; Mazurski, N.; Milana, S.; De Fazio, D.; Eiden, A.; Khurgin, J.; Shappir, J.; Levy, U.; et al. On-Chip Integrated, Silicon-Graphene Plasmonic Schottky Photodetector with High Responsivity and Avalanche Photogain. Nanoletters 2016, 16, 3005-3013. [CrossRef] [PubMed]

29. Casalino, M.; Sirleto, L.; Moretti, L.; Gioffrè, M.; Coppola, G.; Rendina, I. Silicon resonant cavity enhanced photodetector based on the internal photoemission effect at 1.55 micron: Fabrication and characterization. Appl. Phys. Lett. 2008, 92, 251104. [CrossRef]

30. Castagna, M.E.; Coffa, S.; Carestia, L.; Messian, A.; Buongiorno, C. Quantum Dot Materials and Devices for Light Emission in Silicon. In Proceedings of the 32nd European Solid-State Device Research Conference, Firenze, Italy, 24-26 September 2002; pp. 439-442. [CrossRef]

31. Jang, M.; Kim, Y.; Shin, J.; Lee, S. Formation of erbium-silicide as source and drain for decananometer-scale Schottky barrier metal-oxide-semiconductor field-effect transistors. Mater. Sci. Eng. B 2004, 114, 51-55. [CrossRef]

32. Kimata, M.; Ueno, M.; Yagi, H.; Shiraishi, T.; Kawai, M.; Endo, K.; Kosasayama, Y.; Sone, T.; Ozeki, T.; Tsubouchi, N. PtSi Schottky-barrier infrared focal plane arrays. Opto-Electron. Rev. 1998, 6, 1-10.

33. Casalino, M.; Sirleto, L.; Moretti, L.; Gioffrè, M.; Coppola, G.; Iodice, M.; Rendina, I. Back-Illuminated Silicon Resonant Cavity Enhanced Photodetector at 1550 nm. Phys. E Low-Dimens. Syst. Nanostruct. 2009, 41, 1097-1101. [CrossRef]

34. Casalino, M.; Russo, R.; Russo, C.; Ciajolo, A.; Di Gennaro, E.; Iodice, M.; Coppola, G. Free-space graphgene/silicon photodetectors aerating at $2 \mu \mathrm{m}$. ACS Photonics 2018. [CrossRef]

35. Frederick, W. Optical Properties of Solids; Academic Press: Cambridge, MA, USA, 1972; ISBN 9781483220765.

36. Hecht, E. Optics, 4th ed.; Addison-Wesley: Boston, MA, USA, 2002; ISBN 0321188780.

37. Bruggeman, D.A.G. Berechnung verschiedener physikalischer Konstanten von heterogenen Substanzen. I. Dielektrizitätskonstanten und Leitfähigkeiten der Mischkörper aus isotropen Substanzen. Ann. Phys. 1935, 416, 636-664. [CrossRef]

38. Christine, S.; Berini, P. Thin-Film Schottky Barrier Photodetector Models. IEEE J. Quantum Elect. 2010, 46, 633. [CrossRef]

39. Casalino, M. Design of Resonant Cavity Enhanced Schottky Graphene/Silicon Photodetectors at $1550 \mathrm{~nm}$. J. Light. Techno. 2018, 36, 1766-1774. [CrossRef]

40. Sze, S.M.; Ng, K.K. Physics of Semiconductor Devices, 3rd ed.; John Wiley \& Sons: Hoboken, NJ, USA, 2006; ISBN 978-0-471-14323-9. 
41. Silvano, D. Photodetectors: Devices, Circuits and Applications; Prentice Hall: Upper Saddle River, NJ, USA, 2001; Volume 12, ISBN 0-13-020337-8.

42. Llopis, O.; Azaizia, S.; Saleh, K.; Ali Slimane, A.; Fernandez, A. Photodiode 1/f noise and other types of less known baseband noises in optical telecommunications devices. In Proceedings of the Conference: Noise and Fluctuations (ICNF), Montpellier, France, 24-28 June 2013. [CrossRef]

43. Zhu, M.; Li, X.; Li, X.; Zang, X.; Zhen, Z.; Xie, D.; Fang, Y.; Zhu, H. Schottky diode characteristics and 1/f noise of high sensitivity reduced graphene oxide/Si heterojunction photodetector. J. Appl. Phys. 2016, 119, 124303. [CrossRef]

44. Casalino, M.; Sassi, U.; Goykhman, I.; Eiden, A.; Lidorikis, E.; Milana, S.; De Fazio, D.; Tomarchio, F.; Iodice, M.; Coppola, G.; et al. Vertically illuminated, resonant cavity, enhanced graphene-silicon Schottky photodetectors. ACS Nano 2017, 11, 10955. [CrossRef] [PubMed]

C 2018 by the authors. Licensee MDPI, Basel, Switzerland. This article is an open access article distributed under the terms and conditions of the Creative Commons Attribution (CC BY) license (http:/ / creativecommons.org/licenses/by/4.0/). 